\title{
DIFFUSE FIBRO-LEIOMYOMATOUS HAMARTOMATOSIS OF THE LUNG
}

\author{
BY \\ D. BARRON CRUICKSHANK AND G. KENT HARRISON \\ From the Pathological and Surgical Departments, Papworth Sanatorium, Cambridge
}

(RECEIVED FOR PUBLICATION OCTOBER 22, 1952)

This case is one of considerable rarity. The literature on pulmonary hamartomata is almost exclusively limited to the chrondromatous type, in which the cartilage is associated marginally and between fissures with various non-cartilaginous tissues. In these, muscle fibres do not occur very frequently. For example, in 31 cases reported by Rubin and Berkman (1952) strands of smooth muscle were an infrequent finding; in nine cases quoted by Carlsen and Kiaer (1950) strands of smooth muscle were noted in one only; and in reviewing the literature (when describing their own three cases) Bragg and Levene (1950) remark that plain muscle fibres are only occasionally mentioned. Hence the present case, which contains extensive sheets of plain muscle, falls quite outside the usual category.

\section{CASE History}

A painter and smallholder, aged 57, with a family history of diabetes (mother and father), was admitted to Papworth Sanatorium because of a sharp, round radiological opacity, the size of a penny, situated at the level of the anterior end of the third rib just in front of the trachea; tomographs indicated possible areas of calcification. The condition was associated with a winter cough of nine months' duration, a trace of sputum, upper chest discomfort, some fatigue, and a small right supra-clavicular gland. The weight was stationary; micturition, urine, and blood were normal ; there was no clubbing, dyspnoea, or haemoptysis, and the blood pressure was $165 / 80 \mathrm{mg}$. of mercury. The bronchoscopic appearances were normal.

At operation emphysematous bullae were seen covering the apex, a firm palpable mass lay in the upper lobe, and the hilar glands were not enlarged. The upper lobe was found inseparable along part of the oblique and horizontal fissures, and this enforced a pneumonectomy. Immediate convalescence was anxious because of cyanosis and pulmonary oedema, but the patient was discharged two weeks after operation. The residual dyspnoea produced by walking gradually became less over the next six months.

\section{Pathology}

UPPER LOBE.-The "tumour" is situated in the substance of the upper lobe at the junction of the ap:cal and anterior segments $1 \mathrm{~cm}$. below the pleural surface. It is $3 \mathrm{~cm}$. in diameter, has a hard, whitish central core of cartilage, and is surrounded by a thin $(0.2 \mathrm{~cm}$.) layer of soft papillated fibrous tissue covered with respiratory epithelium. The surrounding lung is emphysematous, particularly the apical and posterior segments which, on their rounded vertebral aspect, have developed protruding bullae. Between the tumour and pleura are laterally compressed cystic spaces lined with ciliated epithelium. The adjacent pleura itself over an area of $7 \times 4 \mathrm{~cm}$. is thick and fleshy $(0.5 \mathrm{~cm}$.) and contains some small honeycombed spaces: its outer surface is curiously "hob-nailed" and rough. This thickening (microscopically leiomyomatous) lies tangential to the central cartilaginous mass from which it is completely separated by the intervening lung.

LOWER LOBE.-Over the outer aspects of the lateral and posterior basal segments the lobe is firm and con-

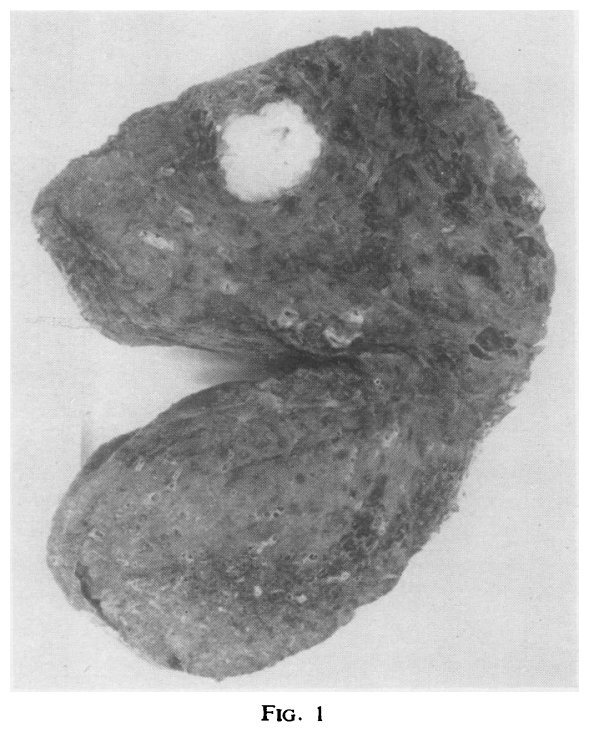


solidated and, on incision, the consolidation is seen to extend inwards for a distance varying from 1 to $3 \mathrm{~cm}$. and to have gross and microscopic appearances similar to those of the thickened pleura in the upper lobe. About one-third of the lower lobe is involved. The apical segment is continuous across the anatomically fused oblique fissure with the upper lobe, and includes a subpleural zone, some $0.5 \mathrm{~cm}$. deep, in which cysts appear ; these cysts become smaller as we pass downwards towards the leiomyomatous consolidation.

MIDDLE LoBE.-There is a leiomyomatous layer, $0.1 \mathrm{~cm}$. deep, under the horizontal fissure with an associated characteristic roughening of the interlobar surface. Otherwise the lobe is normal.

Fig. 1 shows the chondromatous hamartoma in the upper lobe and the thin, dark, subpleural leiomyoma extending along the middle half of this margin, thinning and paling opposite the chondroma. Similar but more extensive leiomyomatous changes show in the lower lobe (darker tint) where one-third is affected. The leiomyomatous condition partially obliterates the oblique fissure. Note also the various bullae, cysts, and honeycomb areas.

Histology.-The central mass is a typical chondromatous hamartoma with clefts and peripheral papillae lined and covered by respiratory epithelium. Chronic inflammatory cells diffuse through its fibro-myxomatous stroma. Mucus-secreting acini appear, and the adja-

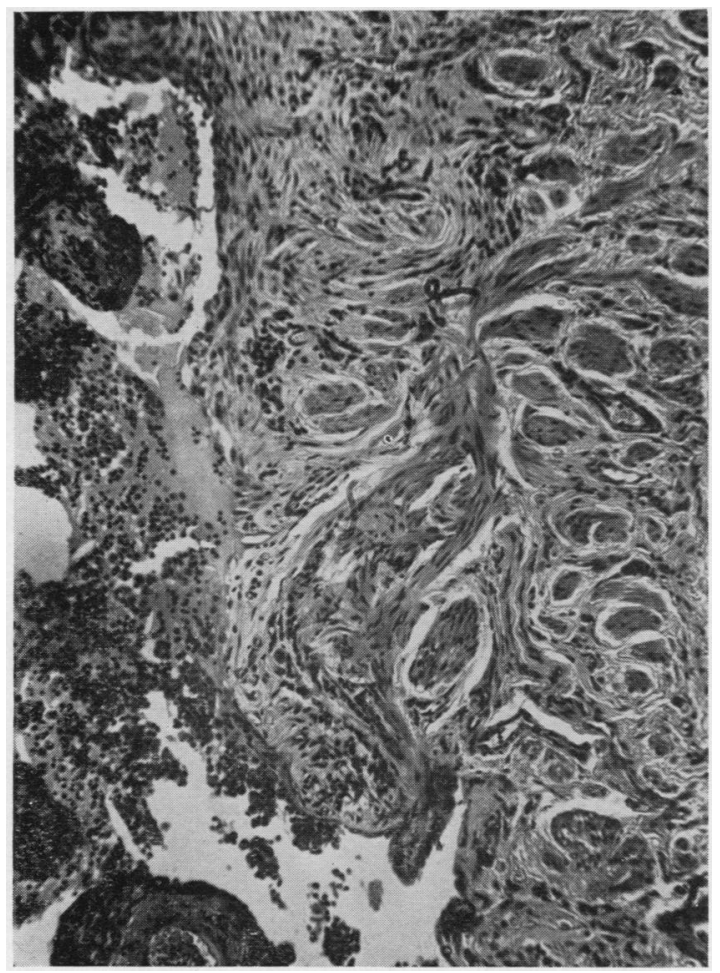

Fig. 2

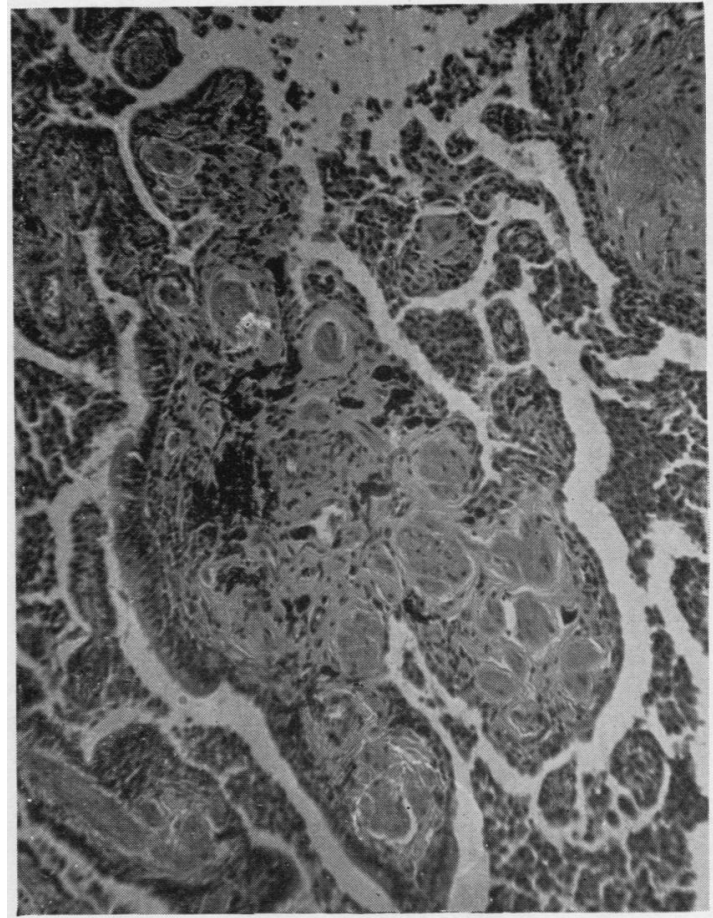

Fig. 3

cent compressed cystic spaces are lined with bronchial ciliated epithelium admixed with many goblet cells.

The unusual features of the pathology relate to the consolidated layers which are quite free of, and in no relation to, the chondromatous mass already described. The primary structure of these unusual areas is fibro-leimyomatous-solid bundles of plain muscle sheathed in moderately thick coverings of fibrous tissue, the whole forming a close network; the strands of this network are cut longitudinally, transversely, and obliquely in the sections. The fibrous sheaths are themselves covered by various respiratory epithelia and the spaces of the network are filled with desquamated alveolar histiocytic cells. In the lower lobe the deeper layers of the leiomyoma contain abnormal bronchial structures, e.g., irregular fibro-muscular tubes, both lined and covered by typical columnar ciliated bronchial epithelium (in transverse section epithelium, fibrous tissue, muscle, fibrous tissue, epithelium).

Much anthracotic pigment lies within the leiomyoma and also elastic fibres. The true overlying pleura is in all cases merely hyalofibrosed.

Fig. 2 shows bundles of plain muscle surrounded by fibrous encapsulations ; bundles are cut transversely and longitudinally. Fig. 3 demonstrates the anthracotic pigment ; interstices are lined by typical columnar ciliated epithelium, or by flatter respiratory epithelium, and the same interstices are filled by masses of desquamated alveolar histiocytic cells. 


\section{Discussion}

The fibro-leiomyoma begins abruptly in the subpleural zone and reaches a maximum density which falls off as we pass inwards; the muscle then vanishes and we are left with a transitional belt of parenchyma, in which the only abnormality is that of interstitial fibrosis; after this comes normal lung. This is the general pattern, which varies only in respect of the width of the subpleural zone affected $(0.5-3 \mathrm{~cm}$.) and of the density of packing (" degree of atelectasis") of the abnormal musculo-fibrous pulmonary elements.

The anthracotic pigment which appears at all levels from pleura to normal lung is notably collected in compact masses in close relation to the irregular abnormal bronchi and vessels of the deeper layers; this would indicate continuity of lymphatics between normal lung, leiomyomatous lung, and the pleura. This fact, taken in conjunction with the histological picture, a distorted arrangement of several normal pulmonary elements, places the condition as diffuse subpleural fibro-leiomyomatous hamartomatosis and not a mere fibro-leiomyomatous infiltration. Other things point in the same direction; for example, leiomyomas of the lung are rare and only some half-dozen cases have been recorded. When they do occur they lead to simple localized encapsulated growths and not to diffuse subpleural sheets (Brahdy, 1941; Williams and Daniel, 1950); even metastatic leimyosarcomas are relatively solid lesions (Willis, 1934). On the other hand, rare diffuse anlagen tumours of tubular structure have been described in the lungs of the newborn (Harris and Schattenberg, 1942).
The lung shows clear evidence of some tendency towards developmental faults, as instanced by the presence of the classical chondromatous hamartoma and of the honeycomb and cystic areas and the fibro-leiomyoma. The aetiological factors causing such defects are believed to relate to functional disturbances associated with, for example, xanthomatosis, tuberous sclerosis, hepatic disease, pituitary disease and the like (Oechsli and Miles, 1934 ; Oswald and Parkinson, 1949; Griffin, Vosseler, and Prentice, 1949; Cunningham and Parkinson, 1950), and in this connexion we should note the diabetic diathesis of both the patient's father and mother.

\section{SUMMARY}

The right lung was removed because of a coinshaped shadow associated with winter cough. This shadow was caused by a classical chondromatous hamartoma in the upper lobe. In addition, all three lobes had extensive areas of pleural hobnailed roughening overlying zones of subpleural consolidation due to diffuse fibro-leiomyomatous changes in the lung. Reasons are advanced for classifying this latter condition as one of true hamartomatosis.

\section{REFERENCES}

Bragg, E. A., and Levene, G. (1950). Radiology, 54, 227

Brahdy, L. (1941). Amer. Rev. Tuberc., 43, 429.

Carlsen C. J., and Kiaer, W. (1950). Thorax, 5, 286.

Carlsen C. J., and Kiaer, W. (1950). Thorax, 5, $286 ., 53$

Cunningham, G. J., and Parkinson, T. (1950). Ibid., 5, 43 J. thorac. Surg., 18, 684.

Harris, W. H., and Schattenberg, H. J. (1942). Amer. J. Path., 18 955

Oechsli, W. R., and Miles, S. H. (1934). Amer. Rev. Tuberc., 30, 239. Oswald, N., and Parkinson, T. (1949). Quart. J. Med, 18. 1

Rubin, M., and Berkman, J. (1952). J. thorac. surg, 23, 393.

Wubin, M., and Berkman, J. (1952). (1950). Ibid., 19, 806 .

Willis, R. A. (1934). The Spread of Tumours in the Human Body, illis, R. A. (1934). The Spread of Tumours in the Human Body,
p. 438. Churchill, London. Quoted in Willis, R. A., Pathology p. 438 . Churchill, London. Quoted
of Tumours, 1948, p. 732. London. 